\title{
Déficits de republicanismo no Brasil: uma crítica à crítica contemporânea
}

\author{
Republicanism deficits in Brazil: a critique of contemporary criticism
}

\author{
Giancarlo Montagner Copelli*
}

\section{REFERÊNCIA}

COPELLI, Giancarlo M. Déficits de Republicanismo no Brasil: uma crítica à crítica contemporânea. Revista da Faculdade de Direito da UFRGS, Porto Alegre, n. 43, p. 119-136, ago. 2020. DOI: https://doi.org/10.22456/0104-6594.95150.

\section{RESUMO}

Muitas são as críticas produzidas por cientistas sociais às teses patrimonialistas no Brasil, assim como àquelas voltadas a explicar nossos déficits republicanos a partir de uma pretensa essência do brasileiro. Também afastando essa essência, este breve ensaio procura, a partir dessa crítica contemporânea, (re)significar, entretanto, as clássicas chaves explicativas não apenas como atuais, mas, ainda, como fundamentais para compreender os limites de concretização do Estado Social no Brasil. Para isso, este artigo argumenta em um único bloco, recuperando a leitura clássica - já dialogada com a crítica na atualidade - para, em seguida, observar o conceito de peemedebismo, do filósofo Marcos Nobre, como atual sequência desse mesmo contexto, que, de resto, parece contribuir para engessar o avanço de direitos sociais. O método aqui empregado é o fenomenológico-hermenêutico.

\section{PALAVRAS-CHAVE}

Republicanismo. Democracia. Patrimonialismo. Peemedebismo.

\begin{abstract}
Many are the critics made by social scientists to the patrimonialism theses in Brazil, as well as those that aim to explain our republican deficits based on an alleged Brazilian essence. Therefore, removing this essence, this brief essay seeks, based on this contemporary criticism, to (re)frame the classic explanatory keys not only as current, but, still, as fundamental to understand the limits of concretization of the Social State in Brazil. Thus, this article argues in a single block, recovering the classic reading - already dialogued with current criticism to then observe the concept of "peemedebismo", by the philosopher Marcos Nobre, as the ongoing sequence of that same context, which seems to contribute to halt the advance of social rights. The performed method is the phenomenological-hermeneutic..
\end{abstract}

\section{KEYWORDS}

Republicanism. Democracy. Patrimonialism. Peemedebismo..

\section{SUMÁRIO}

1. Introdução. 2. O patrimonialismo - para além da crítica contemporânea - e o imobilismo em movimento de Marcos Nobre. 3. Conclusão. Referências. Dados da publicação.

\footnotetext{
" Doutor em Direito pela Universidade do Vale do Rio dos Sinos, mestre em Direito pela Universidade Regional do Noroeste do Estado do Rio Grande do Sul, especialista em Ética e Filosofia Política pela AVM Faculdades Integradas e bacharel em Filosofia pela Universidade do Sul de Santa Catarina. Atualmente em estágio pósdoutoral na Universidade do Vale do Rio dos Sinos.
} 
A Constituição de 1988 aponta para objetivos da República voltados à erradicação da pobreza e à diminuição das desigualdades sociais. Associando esse fim a perseguir à Filosofia da Linguagem de Wittgenstein a uma Teoria de Estado ou Teoria da Democracia ${ }^{1}$, é possível dizer que, com a Carta de Direitos que marca a redemocratização do país, buscou o constituinte instituir uma nova forma de vida, através de um novo jogo de linguagem.

Sem perder de vista a crítica de autores como Avelãs $\mathrm{Nunes}^{2}$, que apontam para o Estado Social como uma espécie de solução de compromisso, em que o Welfare State, no limite, acomodaria as tensões produzidas pela crescente industrialização para, assim, perpetuar o modelo liberal, entendo que, para além disso, o que se tem é o seminal momento em que os níveis de desigualdade encontrados, à época, não eram mais suportados. Daí a necessidade de uma nova forma de vida.

Contudo, passadas mais de três décadas da Carta de 1988, ainda há abissais níveis de disparidade. Embora seja possível perceber um aumento na renda dos mais pobres, também é possível ver o distanciamento dos mais ricos - empurrando as classes médias à pobreza ${ }^{3}$. Para além dessa vinculação entre renda e igualdade material, entretanto, muitos são os direitos sociais - que também promovem melhores níveis de coesão do tecido social - em precário grau de concretização, como permite compreender a crescente judicialização desses mesmos direitos ${ }^{4}$.

Variadas são, nesse sentido, as chaves explicativas a esses déficits, que nublam direitos, como as cíclicas crises entabuladas por Pierre Rosanvallon e, no Brasil, por Bolzan de Morais ${ }^{5}$, além de novos e inéditos contornos limitantes, de efeitos possivelmente permanentes e, embora previsíveis, difíceis de mensurar em impacto, como as profundas

\footnotetext{
${ }^{1}$ COPELLI, Giancarlo Montagner. Construções entre filosofia da linguagem e Teoria do Estado: o Estado Social como Estado de Direito e seus desafios no Brasil. Tese de Doutorado. São Leopoldo: Programa de Pósgraduação em Direito da Universidade do Vale do Rio dos Sinos. 2018.

2 AVELÃS NUNES. António José. As voltas que o mundo dá... Reflexões a propósito das aventuras e desventuras do estado social. Rio de Janeiro: Lumen Juris, 2011

${ }^{3}$ FOLHA DE S. PAULO. Por que o populismo cresce lá fora. Disponível em: http://newsletter.folha.com.br/lafora/201907311800-la-fora.shtml. Acesso em: 01. Ago. 2019. COPELLI, Giancarlo Montagner. Desigualdade social, democracia e direitos humanos: uma leitura da realidade brasileira. (Dissertação de Mestrado). Ijuí: Programa de Pós-graduação em Direito da Universidade Regional do Noroeste do Estado do Rio Grande do Sul, 2014. Ver, especificamente, o capítulo 3.2 - A desigualdade social e o populismo. COPELLI, Giancarlo Montagner. Do sangue ao mérito: os elementos de legitimação da desigualdade no Brasil e as possibilidades de superação pela via democrática [recurso eletrônico]. Santa Cruz do Sul: Editora Essere nel Mondo, 2015.

${ }^{4}$ COPELLI, Giancarlo Montagner. Construções entre filosofia da linguagem e Teoria do Estado. op. cit.

${ }^{5}$ BOLZAN de MORAIS, Jose Luis. As crises do Estado contemporâneo. In: VENTURA, L. América Latina: Cidadania, desenvolvimento e Estado. Porto Alegre: Livraria do Advogado, 1996. ROSANVALLON, Pierre. A crise do estado-providência. Tradução de Joel Pimentel de Ulhôa. Goiânia: UFG, 1997.
} 
transformações no modo de reprodução de nossa vida social, ou seja, no mundo do trabalho ${ }^{6}$. Nesse mesmo sentido, colaboraria a esses limites, no Brasil, o que proponho como déficits de republicanismo, mormente, projetado a partir de autores como, por exemplo, Raymundo Faoro, a nublar a efetivação de direitos sociais, mesmo após a Constituição de 1988.

Muitas são, contudo, as críticas produzidas por cientistas sociais a essas teses, voltadas a explicar nossas carências republicanas a partir de uma pretensa essência do brasileiro. Este breve ensaio procura, portanto, a partir dessa crítica contemporânea e sem desconhecer sua importância acadêmica, (re)significar as clássicas chaves explicativas não apenas como atuais, mas, ainda, como fundamentais para compreender os limites de concretização do Estado Social no Brasil.

Para isso, este artigo vem dividido em duas partes. A primeira recupera a leitura clássica, já dialogando com a crítica na atualidade. A segunda aponta para o conceito de peemedebismo, do filósofo Marcos Nobre, como atual sequência - de 1988 em diante - desse mesmo contexto, que, historicamente, contribui para engessar o avanço de direitos sociais.

Por fim, situando o eventual leitor, informa-se que o método aqui empregado é o fenomenológico-hermenêutico. Tal é embasado a partir de Martin Heidegger e Hans-Georg Gadamer $^{7}$, cuja principal contribuição é justamente romper com as tradicionais estruturas metodológicas à luz da modernidade inaugurada com Descartes ${ }^{8}$. Não há, a partir desses autores, um caminho metodológico definitivo, uma vez que não se pode apreender ou dominar os elementos nele envolvidos ${ }^{9}$.

\footnotetext{
${ }^{6}$ COPELLI, Giancarlo Montagner. Construções entre filosofia da linguagem e Teoria do Estado. op. cit.

7 "Heidegger somente entra na problemática hermenêutica das ciências históricas com a finalidade ontológica de desenvolver, a partir delas, a pré-estrutura da compreensão. Já nós [Gadamer, falando na primeira pessoa do plural], pelo contrário, perseguimos a questão de como, uma vez liberada das inibições ontológicas do conceito de objetividade da ciência, a hermenêutica pôde fazer jus à historicidade da compreensão". GADAMER, HansGeorg. Verdade e Método I: traços fundamentais de uma hermenêutica filosófica. Tradução de Flávio Paulo Meurer. $10^{\text {a }}$ ed. Petrópolis: Editora Vozes, 2008, p. 400 - colchetes nossos.

${ }^{8}$ Projetando um "erro fundamental do desenvolvimento do conceito de sujeito desde Descartes", Heidegger observa que, com "ele começa propriamente a fatalidade da filosofia moderna, porque nele o ego, o eu é de tal forma empobrecido que não é mais nenhum sujeito. O ego sum em Descartes é sem o ser junto a..., sem o serum-com-o-outro. Pois Descartes não chega nem mesmo a colocar a pergunta fundamental, digo, ele não chega nem mesmo a questionar como esse ego é, o que significa esse sum no ego sum em contraposição ao ser, por exemplo, da res extensa". HEIDEGGER, Martin. Introdução à filosofia. Tradução de Marco Antonio Casanova. São Paulo: Martins Fontes, 2008, p. 124 - 125.

${ }^{9}$ STEIN, Ernildo. A questão do método na filosofia: um estudo do modelo heideggeriano. 3 ed. Porto Alegre: Movimento, 1991.
} 


\section{O PATRIMONIALISMO - PARA ALÉM DA CRÍTICA CONTEMPORÂNEA - E O IMOBILISMO EM MOVIMENTO DE MARCOS NOBRE}

A análise dos clássicos voltados a explicar o país, como A Formação Econômica do Brasil, de Celso Furtado ${ }^{10}$, de 1959, A América Latina, Males de Origem, de Manoel Bomfim $^{11}$, publicado originalmente em 1905, Os Donos do Poder, de Raymundo Faoro ${ }^{12}$, publicado pela primeira vez em 1958, O Povo Brasileiro, obra de Darci Ribeiro ${ }^{13}$, de 1964, ou A Formação do Brasil Contemporâneo e História Econômica do Brasil, de Caio Prado Júnior $^{14}{ }^{15}$ - datadas, originalmente, de 1942 e 1945, respectivamente, além de Raízes do Brasil, de Sérgio Buarque de Holanda ${ }^{16}$, publicado em 1936, entre outros, bem como de

\footnotetext{
${ }^{10}$ FURTADO, Celso. Formação econômica do Brasil. Rio de Janeiro: Editora Fundo de Cultura, 1959. A obra aborda ciclos da economia brasileira, como açúcar e café, por exemplo, além de escravidão, imigração e a industrialização do país. Para sua análise, o autor volta sua atenção aos cinco séculos da história do Brasil, buscando no passado as condições de possibilidade para compreender o presente do país.

${ }^{11}$ BOMFIM, Manoel. A América Latina: Males de origem. Rio de Janeiro: Topbooks, 2005. O texto, que data originalmente do início do século XX, pontua os males de origem da América Latina às características sociais da Península Ibérica.

${ }^{12}$ FAORO, Raymundo. Os donos do poder. op. cit. Em linhas muito sucintas, a obra aponta para o período colonial como uma espécie de momento seminal tanto da corrupção quanto do estamento patrimonial, trazidos para cá por Portugal.

${ }^{13}$ RIBEIRO, Darci. O povo brasileiro: a formação e o sentido do Brasil. São Paulo: Companhia das Letras, 2006. Voltado à formação étnica e cultural do Brasil, o antropólogo aponta ainda no primeiro capítulo (O Novo Mundo) para o fato de que os latifúndios existentes no país seriam ainda extensões das possessões portuguesas como se a bula papal Inter Coetera, de 1493, que tornava o chamado Mundo Novo legitimamente possuível por Portugal e Espanha, ainda fosse vigente.

${ }^{14}$ PRADO JUNIOR, Caio. Formação do Brasil Contemporâneo. São Paulo: Editora Brasiliense, 1963. A partir de um viés econômico, o autor procura, nos três séculos do Brasil como colônia da metrópole portuguesa, uma espécie de síntese da formação e constituição do país.

${ }^{15}$ PRADO JÚNIOR, Caio. História econômica do Brasil. 22 ed. São Paulo: Editora Brasiliense, 1979. Também a partir de um viés econômico, o autor aponta para um sistema colonial - pré-capitalista - que perdurou da fase assinalada pela exploração da metrópole portuguesa à Segunda Grande Guerra. Antes, porém, elites formadas no período colonial, como cafeicultores e senhores de engenho, por exemplo, já haviam se constituído como forças capitalistas. Contudo, conservadoras, essas mesmas forças se moldariam como oposição às transformações necessárias ao país. Essas mesmas forças, segundo o autor, se mostrariam como oposição às transformações necessárias ao país até os dias atuais.

${ }^{16}$ HOLANDA, Sérgio Buarque de. Raízes do Brasil. op. cit. Talvez a mais importante obra nesse viés interpretativo, seu texto tem como tese central o personalismo legado pela metrópole portuguesa como obstáculo para a efetivação de uma prática efetivamente republicana no Brasil. Pelo apelo culturalista, a obra é atualmente bastante criticada, sobretudo por autores como Jessé Souza, em trabalhos como A ralé brasileira. op. cit.
} 
autores contemporâneos, guardadas as devidas ressalvas ${ }^{17}$, como José Murilo de Carvalho ${ }^{18}$, com Os Bestializados, de 1987, ou Emilia Viotti da Costa $^{19}$, com seu Da Monarquia à República, por exemplo, permite pensar os dilemas sociais brasileiros a partir de uma espécie de vício de origem, como se, de alguma forma, houvesse uma essência capaz de alinhavar, no horizonte do país, um triste, corrupto e estamental destino.

Nessas chaves explicativas, é possível depreender esse destino já delimitado a partir do Brasil Colônia, percebido como não mais que um enorme empreendimento - uma grande fazenda, como vai assinalar Bomfim ${ }^{20}$-, a ser explorado por Portugal. E daí decorreriam todas as nossas mazelas, com um parasitismo que, desde então, nos acompanha.

De igual modo, é essa mesma condição observada também com o advento da Independência, uma vez que o Brasil deixa de ser colônia para ser império - uma ilha monárquica em meio a uma América cada vez mais republicana -, em que os interesses separatistas eram francamente associados à exploração - ou a uma exploração otimizada das potencialidades da colônia por uma elite constituída já no Brasil - sem relação, portanto, com os ideais liberais que surgiam na Europa -, como pontua Emilia Viotti da Costa ${ }^{21}$. Tal enredo, segundo essa mesma historiadora, colaboraria para - entre outros atributos negativos de origem histórica - a fraqueza de muitas de nossas instituições.

Nesse viés analítico - para encerrar essa espécie de síntese -, é essa mesma condição a lembrada por Murilo de Carvalho ${ }^{22}$, ao chamar a atenção para a carta à imprensa de Aristides Lobo, diante da República proclamada: ato de uma elite forjada no Império e longe de ideais

\footnotetext{
${ }^{17}$ Importa destacar, entretanto, que - segundo Christian Edward Lynch e José Vicente de Mendonça - José Murilo de Carvalho, entre outros, como Antônio Manuel Hespanha e Marcelo Jasmin, é um crítico da "concepção circular do tempo latino-americano, e à hipótese de perene domínio de uma mesma elite ou estamento burocrático séculos afora", como, grosso modo, se estrutura o patrimonialismo desenhado por Raymundo Faoro. LYNCH, Christian Edward Cyril; MENDONÇA, José Vicente Santos de. Por uma história constitucional brasileira: uma crítica pontual à doutrina da efetividade. Revista Direito e Práxis, v. 8, n. 2, p. 942-973, 2017. Disponível em: http:/www.e-publicacoes.uerj.br/index.php/revistaceaju/article/view/25654. Acesso em: 04 jan. 2018. Nesse mesmo sentido, ver, também, CARVALHO, José Murilo de. A construção da ordem e Teatro de sombras. Rio de Janeiro: Editora UFRJ/Relume Dumará, 1996. Nesta obra, há uma contundente crítica do autor ao conceito de estamento, de Faoro.

${ }^{18}$ CARVAlHO, José Murilo de. Os bestializados: o Rio de Janeiro e a república que não foi. São Paulo: Companhia das Letras, 1987. Buscando entrelaçar três temas - o regime político (república), o Rio de Janeiro (cidade) e a prática popular (cidadania), o autor aponta para o fato de que os três temas, do advento da República para cá, permanecem dissociados.

${ }_{19}$ COSTA, Emilia Viotti da. Da Monarquia à República: momentos decisivos. 5 ed. São Paulo: Editora Brasiliense, 1987, p. 15. Debruçada à história do país a partir da crise do sistema colonial, ou seja, do momento que permite a passagem à independência - como monarquia, inicialmente -, a historiadora procura, como bem salienta no fim da introdução do texto, "entender a fraqueza das instituições democráticas e da ideologia liberal, assim como a marginalização política, econômica e cultural de amplos setores da população brasileira, problemas básicos do Brasil contemporâneo".

${ }^{20}$ BOMFIM, Manoel. A América Latina. op. cit.

${ }^{21}$ COSTA, Emilia Viotti da. Da monarquia à república. op. cit.

${ }^{22}$ CARVALHO, José Murilo de. Os bestializados. op. cit.
} 
de cidadania, o novo regime, entre tantas e variadas significações, veio com o povo à margem do processo em que deveria ser protagonista. Sem saber do que se tratava, esse mesmo povo relatou o propagandista republicano em texto enviado ao Diário Popular em 18.11.1889 julgou estar diante de uma parada militar. Por uma espécie de vício de origem - talvez bem resumido pelo lamento de Aristides Lobo -, a república não republicanizou - diria Murilo de Carvalho -, mantendo-se, até hoje, dissociada da cidadania.

Embora esse vício não encerre em si um certo traço congelante da História - quero dizer, poderia ter sido diferente - Colônia, Império e Primeira República teriam, entretanto, forjado as transformações que caracterizam cada período a partir de vínculos personalistas ${ }^{23}$, baseados em uma espécie de sistema de privilégios. Em que pese não se trate de uma mesma elite, como parecem sustentar as teses patrimonialistas - sobretudo, com Faoro -, esse mesmo sistema de favorecimentos, no passado, determinaria o presente e condenaria o futuro, enredados por um traço culturalista que não apenas forja uma essência ao brasileiro, como também permite contraditoriamente perpetuar - ou até mesmo legitimar - a desigualdade e a corrupção que parecem nos moldar.

É desse ponto em diante que autores contemporâneos, como o sociólogo Jessé Souza $^{24}$, lançam suas críticas ao patrimonialismo. Considerando-o mais uma ideologia projetada "por parte da elite paulista vencida por Vargas em 1930, no sentido de construir uma teoria e uma elite intelectual e política antiestatal e liberalizante, como discurso legitimador para a reconquista do poder político perdido", o patrimonialismo, ao demonizar o Estado como lócus privilegiado de corrupção e de relações pessoalizadas na prática institucional, seria ainda o discurso que, revestido de crítica da realidade, permitiria a manutenção de uma série de privilégios a determinados grupos.

Esse mesmo viés encontra eco no de Christian Lynch e José de Mendonça ${ }^{25}$, ao fazerem uma crítica à doutrina da efetividade de Luís Roberto Barroso - e, consequentemente, à tese do patrimonialismo - segundo eles, espécie de teoria de base para a proposta do ministro do STF. De acordo com tais autores, "esses ensaios [como Os Donos do Poder] se pautavam por uma imaginação política, que oscilava entre o teórico e o ideológico”. Assim

\footnotetext{
${ }^{23}$ Personalismo ou culto à personalidade que, segundo Ferreira, é a tendência de valorização da autonomia e da negação a formas de dependência e hierarquia ou, segundo Souza, como uma forma de sociabilidade que enfatiza os vínculos pessoais, através de sentimentos como amizade e ódio. FERREIRA, Gabriela Nunes. A formação nacional em Buarque, Freyre e Vianna. Lua Nova, n. 37, p. 229-247, 1996. Disponível em: http://www.scielo.br/pdf/ln/n37/a12n37.pdf. Acesso em: 18 mar. 2014.

SOUZA, Jessé. A ralé brasileira. op. cit.

${ }^{24}$ SOUZA, Jessé. A ralé brasileira. op. cit., p. 65.

${ }^{25}$ LYNCH, Christian Edward Cyril; MENDONÇA, José Vicente Santos de. Por uma história constitucional brasileira. op. cit.
} 
como para o autor de $A$ ralé brasileira, textos como o de Faoro buscavam, para eles, "compreender as causas do atraso brasileiro, criticando sua realidade atual para encaminhar a opinião pública a favorecer determinados projetos político-sociais"26.

É evidente, pensar o Brasil através dessas chaves explicativas - talvez inauguradas com Sergio Buarque de Holanda ${ }^{27}$ e seu Raízes do Brasil, mas com o ápice em Raymundo Faoro $^{28}$ e $O s$ donos do poder - não apenas favorece o discurso antiestatal - de acordo com Souza, próprio das elites paulistas, derrotadas por Vargas -, mas também faz caminhar a uma espécie de destino inexorável: aculturando e oferecendo essência ao brasileiro, o passado molda o presente e determina o futuro. Relativiza, naturaliza condutas e, também por isso, legitima padrões, paradoxalmente, de corrupção e privilégios.

Esse posicionamento, aliás, é compartilhado por Lilia Schwarcz e Heloisa Starling. Ao concluir Brasil: uma biografia, as autoras observam que, na esteira desse enredo patrimonialista, “o Brasil seria forçosa e definitivamente corrupto devido a certas práticas e comportamentos - o 'jeitinho', a malandragem, o político ladrão - que, desde sempre presentes na nossa história, fazem parte de um suposto caráter do brasileiro" ${ }^{29}$. E destacam: "Essa abordagem, além de preconceituosa, naturaliza a corrupção no país, simplifica e congela sua compreensão, assim como impede o combate a um fenômeno de alta complexidade" 30 .

Diante dessas aproximações - de Souza a Schwarcz e Starling -, não se desconhecem, portanto, as críticas a essas tentativas de explicar o Brasil - e nem se pretende insistir nessas possibilidades interpretativas de forte apelo entre 1922 e 1970, "anteriores", como ponderam Lynch e Mendonça, "ao amadurecimento das ciências sociais no Brasil" ${ }^{31}$. Mas, ao tratar de déficits de republicanismo como entrave ao Estado Social - como proponho aqui -, é preciso não perder de vista que "práticas patrimoniais e clientelistas resistem no interior do sistema político e nas instituições públicas" ${ }^{32}$ não como algo imutável - forjado como essência, portanto -, mas como aquilo que, rotineiramente, se percebe no interior dessas mesmas instituições.

\footnotetext{
${ }^{26}$ LYNCH, Christian Edward Cyril; MENDONÇA, José Vicente Santos de. Por uma história constitucional brasileira. op. cit., p. 991.

${ }^{27}$ HOLANDA, Sergio Buarque. Raizes do Brasil. op. cit.

${ }^{28}$ FAORO, Raymundo. Os donos do poder. op. cit.

${ }^{29}$ SCHWARCZ, Lilia Moritz e STARLING, Heloisa Murgel. Brasil. op. cit., p. 504.

${ }^{30}$ SCHWARCZ, Lilia Moritz e STARLING, Heloisa Murgel. Brasil. op. cit., p. 504.

${ }^{31}$ LYNCH, Christian Edward Cyril; MENDONÇA, José Vicente Santos de. Por uma história constitucional brasileira. op. cit., p. 991.

${ }^{32}$ SCHWARCZ, Lilia Moritz e STARLING, Heloisa Murgel. Brasil. op. cit., p. 502.
} 
Isso, evidentemente, é esboçado a partir de jogos (muito particulares) de linguagem, próprios de atores que se apropriam do público como se privado fosse. É aí que se tem o patrimonialismo à margem de uma essência que o naturaliza, concorrendo, no mesmo espaço, com o acordo político cristalizado na Constituição de 1988. Afinal, se, por um lado, Schwarcz e Starling engrossam o coro que refuta uma espécie de essência que naturaliza a corrupção, por outro essas mesmas autoras reconhecem que essa prática está "longe de ser um fenômeno marginal na vida pública brasileira. [...]. A história recente", completam, "é pródiga em exemplos" ${ }^{33}$.

À margem - mas não alheia - a essa associação entre patrimonialismo e corrupção, contudo, apropriada à tese que procuro, aqui, assentar, é a leitura de Lenio Streck no primeiro capítulo de seu Hermenêutica Jurídica e $(m)$ Crise $^{34}$, ao apontar o Welfare State não como instrumento voltado à igualdade ${ }^{35}$, mas como alavanca de crescimento às camadas médiosuperiores da sociedade brasileira. Sobre isso, discorre esse autor: "O Estado [...], que deveria fazer essa função social, foi - especialmente no Brasil - pródigo (somente) para com as elites [...], que se apropriaram/aproveitaram de tudo desse Estado, privatizando-o, dividindo/loteando com o capital internacional os monopólios e os oligopólios da economia"36. A partir dessa assertiva, Streck, ao dar exemplos - que vão desde juros subsidiados com o FGTS (e sequer pagos até o fim dos contratos) para a construção de imóveis a essas mesmas camadas sociais à discrepância entre as famílias consideradas muito ricas no Brasil (com patrimônio correspondente a quase a metade do PIB) -, questiona: "Por que atingimos esse grau de desigualdade? E por que o Estado brasileiro é o lócus da dilapidação da res publica?" ${ }^{37}$.

\footnotetext{
${ }^{33}$ Anterior à queda da presidente Dilma Rousseff, as autoras não se furtam aos exemplos - entre outros, também relacionados no último capítulo desse estudo, sob a ótica de outros autores: "Acusações de manipulação e corrupção foram feitas durante o governo FHC, e estão relacionadas, sobretudo, à venda de empresas estatais públicas - BNDES, Telebras, Companhia Vale do Rio Doce - e à compra de votos de parlamentares para garantir a reeleição do presidente da República. No primeiro mandato de Lula explodiu a denúncia do 'mensalão' - o pagamento mensal a deputados de diversos partidos para a compra de apoio parlamentar ao governo -, que envolveu alguns dos principais dirigentes do PT e geraria posteriormente a prisão de membros da elite política e econômica do país. [...] Já no final do primeiro governo de Dilma Rousseff vieram a público as operações de corrupção ativa, lavagem de dinheiro, formação de quadrilha e incompetência gerencial na Petrobras. SCHWARCZ, Lilia Moritz e STARLING, Heloisa Murgel. Brasil. op. cit., p. 504-505.

${ }^{34}$ STRECK, Lenio Luiz. Hermenêutica Jurídica e $(m)$ crise. op. cit.

${ }^{35}$ Segundo Walter de Moura Agra, a igualdade é um dos alicerces para um conceito de republicanismo. Em obra voltada ao tema, publicada na Coleção Estado \& Constituição e coordenada por Jose Luis Bolzan de Morais, o autor, ao conceituar republicanismo, o põe não apenas como aquele que se estrutura pela negação de qualquer tipo de dominação, pela defesa das virtudes cívicas e pela construção de um Estado de Direito, incentivando aos indivíduos o autogoverno, mas aquele voltado a "implementação de políticas que atenuem a desigualdade social, através da efetivação da isonomia substancial". AGRA, Walber de Moura. Republicanismo. op. cit., p. 16.

${ }^{36}$ STRECK, Lenio Luiz. Hermenêutica Jurídica e $(m)$ crise. op. cit., p. 28.

${ }^{37}$ STRECK, Lenio Luiz. Hermenêutica Jurídica e (m) crise. op. cit., p. 30.
} 
A interrogação é pertinente. Embora longe de pensar essa dilapidação, circularmente, a partir de uma mesma elite perpetuada por séculos, para o autor de Hermenêutica Jurídica $e(m)$ Crise a resposta encontra eco nas teses de Faoro. Sem associar tais teorias à pretensão de uma essência do brasileiro - o que, aliás, seria um contrassenso para um hermeneuta da tradição de Heidegger e Gadamer -, Streck projeta o Estado como patrimonialista "porque os titulares do poder [a elite, ou fatia dela que, de resto, se amolda às circunstâncias, como o próprio Faoro já observava ${ }^{38}$ ] se apoderam do aparelhamento estatal de tal forma que acaba por gerar uma quase indistinção do que é público (Estado) e o que é privado" ${ }^{39}$.

Buscando colar, mais uma vez, tal projeção a exemplos, o jurista faz referência ao professor do Insper - Instituto de Ensino e Pesquisa -, Sérgio Lazzarini, e seu Capitalismo de laços: os donos do Brasil e suas conexões ${ }^{40}$. Dele, extrai o case envolvendo "a investida do governo no Fundo de Pensão Previ e do empresário Eike Batista sobre os administradores da Vale do Rio Doce, empresa privatizada no governo Fernando Henrique Cardoso por um valor simbólico" ${ }^{41}$. E, a partir daí, encadeia ideias que demonstram com clareza a apropriação do público pelo privado: "Em tese, a Vale é uma empresa privada. Na prática [...], o governo é seu maior acionista, e Eike Batista era seu melhor amigo. Em 2008, foi o maior financiador do filme Lula, o filho do Brasil e, em 2006, o maior doador individual da campanha que reelegeu Lula. E o maior doador corporativo foi a empresa 'privada' Vale"42.

No mesmo sentido, em parceria com Aldo Musacchio, Lazzarini ${ }^{43}$, em obra buscando respostas à forma de evolução do capitalismo de Estado, traz outro interessante exemplo do embaralhamento entre o público e o privado, chamando à luz das discussões um ator (privado) que, em 2017, esteve no epicentro de mais um escândalo (público): a $J B S^{44}$. Voltando a 2007, esses autores lembram a aquisição - por 1,4 bilhão de dólares - da Swift \& Co. por uma empresa brasileira, a própria $J B S$, que, à época, seguramente não figurava entre as mais

\footnotetext{
${ }^{38}$ No último capítulo de Os donos do poder, Faoro observa, precisamente, que o "patrimonialismo se amolda às transições, às mudanças". FAORO, Raymundo. Os donos do poder. op. cit., p. 823-824.

${ }^{39}$ STRECK, Lenio Luiz. Hermenêutica Jurídica e(m) crise. op. cit., p. 30.

${ }^{40}$ LAZZARINI, Sérgio G. Capitalismo de laços: os donos do Brasil e suas conexões. Rio de Janeiro: Elsevier, 2011.

${ }^{41}$ STRECK, Lenio Luiz. Hermenêutica Jurídica e(m) crise. op. cit., p. 31.

${ }^{42}$ STRECK, Lenio Luiz. Hermenêutica Jurídica e(m) crise. op. cit., p. 31.

${ }^{43}$ MUSACCHIO, Aldo; LAZZARINI, Sérgio. Reinventando o capitalismo de Estado. O Leviatã nos negócios: Brasil e outros países. Tradução de Afonso Celso da Cunha Serra. 1 ${ }^{a}$ ed. São Paulo: Portfolio-Penguin, 2015.

${ }^{44}$ De acordo com a $B B C$ Brasil, a JBS é alvo de cinco operações da Polícia Federal, investigando o pagamento de propina a agentes públicos. Siglas, como PT, PMDB, PSDB e PDT aparecem nas investigações. Ainda segundo a BBC, Joesley Batista, maior acionista da empresa, teria dito em delação que a propina era para conseguir a boa vontade da classe política. BBC BRASIL. Guia da delação da JBS: entenda as acusações que abalaram o mundo político. Disponível em: http:/www.bbc.com/portuguese/brasil-39983080. Acesso em: 10 jan. 2018.
} 
significativas do mercado ${ }^{45}$. Mas - observam esses autores -, a partir dessa aquisição, a empresa tornou-se a maior processadora de carnes do mundo. Dois anos depois, em 2009, outra aquisição, desta vez, por 2,8 bilhões de dólares, incorporando a Pilgrim's Pride e consolidando-se definitivamente no topo do setor. Diante desse enredo, a questão levantada por Musacchio e Lazzarini é: "Onde uma empresa brasileira mais ou menos desconhecida teria obtido os fundos necessários para financiar essas aquisições?’. A resposta é a chave da discussão: “O Banco Nacional de Desenvolvimento Econômico e Social - empresa pública federal brasileira, conhecida como BNDES - escolheu a JBS como 'campeã nacional' e concedeu-lhe financiamento para tornar-se ator dominante no mercado global de carne bovina e de frango" $"$.

O negócio entre a empresa privada e a instituição pública - orientado por atores de ambos os lados - define o conceito de capitalismo de Estado. Significativo para as questões envolvendo mercado e competitividade, é esse mesmo conceito também importante para se pensar esses déficits de republicanismo. Afinal, se capitalismo de Estado é " a influência difusa do governo na economia, seja mediante participação acionária minoritária ou majoritária nas empresas, seja por meio do fornecimento de crédito subsidiado elou de outros privilégios a negócios privados" ${ }^{47}$, caracterizada está a apropriação do público como se privado fosse, em uma via de mão-dupla: de um lado, o privilégio ao negócio privado. De outro, o Estado como ator econômico, atuando no mercado atrás, basicamente, de dividendos políticos ${ }^{48}$ que, no mais, servem à pretensão de manutenção do poder.

Com esses cases - da Vale do Rio Doce à $J B S$-, o que quero mostrar são esses mesmos déficits muito além dos evidentes e constantes episódios de corrupção que, somente

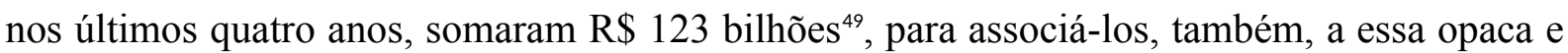
historicamente verificada indistinção entre o público e o privado. Não se trata de uma tradição ou uma peculiaridade brasileira - o capitalismo de Estado é um fenômeno mais ou menos

\footnotetext{
${ }^{45}$ Mas que, somente este ano, de janeiro de 2019 ao início de agosto do mesmo ano, cresceu 187,44\%, tornandose um dos papeis listados na Bolsa brasileira mais atraentes aos investidores.

${ }^{46}$ MUSACCHIO, Aldo; LAZZARINI, Sérgio. Reinventando o capitalismo de Estado. op. cit., p. 09.

${ }^{47}$ MUSACCHIO, Aldo; LAZZARINI, Sérgio. Reinventando o capitalismo de Estado. op. cit., p. 10.

${ }^{48}$ Ponderam os autores, a partir do analista político Ian Bremmer. MUSACCHIO, Aldo; LAZZARINI, Sérgio. Reinventando o capitalismo de Estado. op. cit.

${ }^{49}$ Segundo o jornal O Estado de São Paulo, de 2013 a 2017 os prejuízos envolvendo a corrupção totalizaram R\$ 123 bilhões, conforme dados da Diretoria de Investigação e Combate ao Crime Organizado. De acordo com o periódico paulista, o "quadro é o resultado da conta feita pelos investigadores federais com base em valores de contratos fraudulentos, impostos sonegados, crimes financeiros e cibernéticos, verbas públicas desviadas e até mesmo danos ambientais causados por empresas, madeireiras e garimpos. Tudo misturado ao pagamento de propina a agentes públicos e políticos". ESTADO DE SÃO PAULO. Organizações criminosas deixam rombo de $R \$ 123 \mathrm{bi}$. Disponível em: http://politica.estadao.com.br/noticias/geral,organizacoes-criminosas-deixamrombo-de-r-123-bi,70001846542. Acesso em: 18 jan. 2018.
} 
global -, menos ainda de uma essência, mas de uma tibieza institucional que se arrasta no tempo e impede, para voltar à expressão de Murilo de Carvalho, a república de se republicanizar ${ }^{50}$.

Uma república que não republicaniza não pode, enfim, remeter à significação de coisa pública e, ainda mais, àquilo que é de interesse comum, em oposição ao público pensado como se privado fosse. Eis o ponto, aliás, capaz de deslocar a ideia de patrimonialismo - de crítica social moderna à teoria criticada na contemporaneidade - para além dos limites que originalmente lhe emprestaram forma ${ }^{51}$.

Nesse sentido, mais que a corrupção possível de ser auferida em números e nas negociatas envolvendo atores públicos e privados - em esquemas de viés, de ambos os lados, particulares -, se tem no próprio sistema político e nas suas instituições uma espécie de lugar para esses mesmos déficits. É que se patrimonialismo é a apropriação do público pelo privado, o próprio funcionamento das siglas partidárias, trocando governabilidade por bolsões de poder, faz do espaço público um balcão de negócios. É, ao menos, o que se depreende, na contemporaneidade, do conceito de peemedebismo, cunhado pelo filósofo Marcos $\mathrm{Nobre}^{52}$, e que talvez melhor reflita os déficits de republicanismo verificados no Brasil, como, segundo ele, uma cultura mesmo e - como se verá adiante - como uma forma de herança, ainda que recente.

Buscando atualizar a discussão a partir desse autor, o contexto do peemedebismo surge com o declínio da ditadura militar. É a partir daí que um novo jogo de linguagem buscando instituir uma nova forma de vida - para usar os conceitos da Filosofia da Linguagem de Wittgenstein colados a uma Teoria de Estado ou Teoria da Democracia ${ }^{53}-$ passa a ganhar contornos. A desigualdade, nos moldes até então verificados, tornou-se insustentável, abrindo espaço para um novo pacto. Na transição de modelos, ou seja, na passagem a essa nova forma de vida, entretanto, "do ponto de vista das elites do poder, passou

\footnotetext{
${ }^{50}$ CARVALHO, José Murilo de. Os bestializados. op. cit.

${ }^{51}$ Basicamente, centrada na apropriação de um determinado espaço por um senhor, que fatia esse mesmo lugar entre os seus, buscando com isso, manter tanto o poder como as relações no seu entorno pessoalizadas. Os dividendos percebidos pelas peças dispostas a seu comando são, notadamente, projetados a partir do espaço público. Essa tese não desconsidera essa espécie de conceito, mas também o propõe como simplesmente a apropriação do público como se privado fosse.

${ }^{52}$ NOBRE, Marcos. Imobilismo em movimento: Da abertura democrática ao governo Dilma. 1 ed. São Paulo: Companhia das Letras, 2013, p. 11. "Não se trata de restringir essa cultura política à prática de um único partido. Denominar assim a cultura política dominante deve-se ao fato de seu modelo ter sido primeiramente gestado no período em que o PMDB teve posição de dominância na década de 1980. Depois disso, a partir da década de 1990, já refuncionalizado, o peemedebismo se destacou do partido em que foi gestado inicialmente, passando a moldar o sistema político de maneira mais ampla".

${ }^{53}$ COPELLI, Giancarlo Montagner. Construções entre filosofia da linguagem e Teoria do Estado. op. cit.
} 
a ser essencial pelo menos o controle da velocidade e da amplitude de diminuição das desigualdades". Mas, de fato, como isso ocorreu? Ainda, como a mudança pretendida com a redemocratização foi controlada? De acordo com Nobre, através de "uma cultura política que se estabeleceu nos anos 1980 e que, mesmo se modificando ao longo do tempo, estruturou e blindou o sistema político contra as forças sociais de transformação" ${ }^{54}$, a partir da construção de supermaiorias parlamentares voltadas a emprestar condição de governabilidade. Foi através dessas "grandes coalizões" - sufocando a linguagem pública compreendida como política que o "sistema conseguiu se perpetuar buscando ignorar o conflito social e atraindo mais e mais aliados por meio da oferta de cargos no governo". É através dessas posições que se controla, claro, "parte da despesa pública" e, consequentemente, se evita "a influência da esfera pública". Não por acaso, o sistema procurou, desse modo, "se perpetua[r] sem incorporar novas demandas sociais, tendo que lidar apenas com interesses individuais no controle do orçamento por políticos aliados" $" 55$.

Como se vê, temos uma república que não republicanizou na sua gênese, portanto, mas que também, mesmo com a redemocratização, não pôde - como de resto, parece ainda não poder - republicanizar. Ou, como diria Nobre no sugestivo título de sua obra, um imobilismo em movimento, cujo start é justamente a continuidade de uma "ideologia oficial [...], controlada pelo regime ditatorial em crise e pactuada de cima por um sistema político elitista" ${ }^{56}$.

Nesse mesmo sistema político - que de resto iniciou com a Segunda República e o multipartidarismo que, entre outros fatores, a caracterizou ${ }^{57}$, o que se tem é a venda de apoio parlamentar, cuja moeda de troca é, evidentemente, pública e dependente da institucionalização de atores também no espaço público. Ou seja, embora claramente não se

\footnotetext{
${ }^{54}$ NOBRE, Marcos. Imobilismo em movimento. op. cit., p. 10 - grifo nosso.

${ }^{55}$ RODRIGUEZ, José Rodrigo. Sociedade contra o Estado - duas ondas de democratização radical no Brasil (1988 e 2013): uma interpretação à luz de Franz Neumann. In: STRECK, Lenio Luiz; ROCHA, Leonel Severo; HENGELMANN, Wilson (Orgs.). Constituição, sistemas sociais e hermenêutica: anuário do Programa de Pósgraduação em Direito da Universidade do Vale do Rio dos Sinos - UNISINOS - Mestrado e Doutorado. Porto Alegre: Livraria do Advogado, 2016, p. 89.

${ }^{56}$ NOBRE, Marcos. Imobilismo em movimento. op. cit., p. 11.

${ }^{57}$ Nessa cultura política referida por Nobre e verificada com o impeachment de Collor, o chamado Centrão, que se mostraria necessário para barrar o processo, foi tardiamente mobilizado; em 1993, com a construção do chamado acordo de governabilidade, estendeu-se aos governos Itamar Franco e Fernando Henrique Cardoso. Verificou-se também com Lula, em 2005, no escândalo do mensalão, quando a construção de maiorias parlamentares se mostrou decisiva para bloquear o impeachment, e com Dilma, a partir de 2011, como o instrumento de governabilidade que não se verificou na interrupção de seu segundo mandato. Atualmente, é possível observar significativa tensão entre o Congresso e a agenda da presidência, notadamente, diante desse mesmo modelo de organização e exercício do poder.
} 
trate de demonizar o Estado - como fazem supor as críticas aqui discutidas -, essas interações não ocorrem fora desses mesmos espaços públicos.

Assim, o que se tem é um sistema, uma cultura e um contexto, mas, ainda, também uma sutil herança. De roupagem diversa, ela se mostra travestida de um imobilismo em movimento que, através do tempo, manteve os traços de colônia na Independência - ou uma enorme fazenda igualmente após ruptura com a metrópole -, moldando posteriormente uma república que não se republicanizou, fazendo do pacto possível com a Constituição de 1988, portanto, uma abstração sobre direitos sociais que não se pôde converter, de fato, em uma forma de vida - para mais uma vez utilizar o termo wittgensteiniano. De fato, em cada etapa, uma forma de imobilismo. Embora refira-se a um tempo específico, o termo de Nobre não poderia ser melhor. São contextos de contornos estanques que vêm, afinal, moldando o país ao longo do tempo, fazendo do Brasil o país e as suas circunstâncias - parafraseando, aqui, Ortega y Gasset ${ }^{58}$.

Eis o ponto. Uma herança, sem dúvidas, mas que não só pode como deve ser recusada. Afinal, novamente a partir do pensador espanhol, é preciso ter claro: o país é aberto à realidade que o cerca, mas não se constitui na própria circunstância. A realidade é diversa do ser. Salvar a circunstância, como indicaria o filósofo, é compreendê-la. Não significa perpetuá-la. Assim, caminhando a um desfecho, se a circunstância não se confunde com o ser, a herança não engessa a pretensa essência do brasileiro. Não há, aliás, essência. Que fique claro. E é por isso, enfim, que a herança pode - e deve - ser recusada.

\section{CONCLUSÃO}

Evidentemente, a tese da herança carrega significativos déficits. Um deles é o deslocamento - ou melhor, a aniquilação - do tempo, propondo uma espécie de relação circular das circunstâncias, em que o passado determina o passado e condena o futuro. Não desconheço as críticas que caminham nesse sentido. Mais: considero-as válidas. Afinal, para além desse engessamento, essas mesmas posições teriam a capacidade de naturalizar determinadas práticas na frágil relação entre o público e o privado no país. Paradoxalmente, portanto, agravariam justamente os problemas que pretensamente projetam denunciar.

Por outro lado - e é isso que move esse pequeno ensaio - considero igualmente que culturas, heranças, contextos e circunstâncias não são alicerces de um destino inexorável, ao

\footnotetext{
${ }^{58}$ ORTEGA Y GASSET, José. Meditaciones del Quijote: con un apéndice inédito. Revista de Occidente en Alianza Editorial, 1981.
} 
contrário. Como procurei até aqui argumentar, se o anseio da comunidade política é a transformação, ou seja, é a instituição de uma nova forma de vida, então essas pretensas heranças devem efetivamente ser recusadas. Percebê-las é tão-somente o reconhecimento de uma circunstância que, por séculos, nos acompanha, como mesmo vão dizer Starling e Schwartz. Nada há, enfim, que engesse seu sentido - como seria de se supor a partir de um certo traço da velha metafísica clássica. Não se trata disso.

Por outro lado, nesse mesmo enredo, se patrimonialismo é a apropriação do público pelo privado, variadas são as formas de se auferi-lo, assim como, muito por ele, se caracterizam os déficits de republicanismo verificados no Brasil: da república que não republicaniza de Murilo de Carvalho ao imobilismo em movimento de Marcos Nobre, o que se tem é um histórico contexto de satisfação de interesses próprios a partir de paralelos e individualizados jogos de linguagem a ocupar o espaço público, efetivamente, como se vê, colonizado por uma série de particularismos. Perceber essa circunstância, insisto, não significa demonizar o Estado - e erguer, por conseguinte, templos a dimensões privadas. Aliás, como de resto se viu nesse breve texto, é sobretudo a partir desses mesmos espaços que se esboçam as condições de possibilidade para um capitalismo de laços, voltando à expressão de Sérgio Lazzarini. De todo modo, é dessa relação - em que o Estado é apenas uma parte, bem descrita, na contemporaneidade, por Marcos Nobre -, que se percebe o bloqueio das efetivas condições de possibilidade para novas e efetivas formas de vida, projetadas politicamente pela Constituição de 1988 e dependentes, claro, do barramento de circunstâncias e contextos que, enfim, devem ser recusados.

\section{REFERÊNCIAS}

AVELÃS NUNES. António José. As voltas que o mundo dá... Reflexões a propósito das aventuras e desventuras do estado social. Rio de Janeiro: Lumen Juris, 2011.

BBC BRASIL. Guia da delação da JBS: entenda as acusações que abalaram o mundo politico. Disponível em: http://www.bbc.com/portuguese/brasil-39983080. Acesso em: 10 jan. 2018.

BOLZAN DE MORAIS, Jose Luis. As crises do Estado contemporâneo. In: VENTURA, L. América Latina: Cidadania, desenvolvimento e Estado. Porto Alegre: Livraria do Advogado, 1996.

BOMFIM, Manoel. A América Latina: Males de origem. Rio de Janeiro: Topbooks, 2005. 
CARVALHO, José Murilo de. Os bestializados. O Rio de Janeiro e a república que não foi. São Paulo: Companhia das letras, 1987.

CARVALHO, José Murilo de. A construção da ordem e Teatro de sombras. Rio de Janeiro: Editora UFRJ/Relume Dumará, 1996.

COPELLI, Giancarlo Montagner. Do sangue ao mérito: os elementos de legitimação da desigualdade no Brasil e as possibilidades de superação pela via democrática [recurso eletrônico]. Santa Cruz do Sul: Editora Essere nel Mondo, 2015.

COPELLI, Giancarlo Montagner. Desigualdade social, democracia e direitos humanos: uma leitura da realidade brasileira. (Dissertação de Mestrado). Ijuí: Programa de Pós-graduação em Direito da Universidade Regional do Noroeste do Estado do Rio Grande do Sul, 2014.

COSTA, Emilia Viotti da. Da Monarquia à República: momentos decisivos. 5 ed. São Paulo: Editora Brasiliense, 1987.

ESTADO DE SÃO PAULO. Organizações criminosas deixam rombo de $R \$ 123$ bi. Disponível em: http://politica.estadao.com.br/noticias/geral,organizacoes-criminosas-deixamrombo-de-r-123-bi,70001846542 . Acesso em: 18 jan. 2018.

FAORO, Raymundo. Os donos do poder: formação do patronato político brasileiro. 5.ed. São Paulo: Globo, 2012.

FERREIRA, Gabriela Nunes. A formação nacional em Buarque, Freyre e Vianna. Lua Nova, n. 37, p. 229-247, 1996. Disponível em: http://www.scielo.br/pdf/ln/n37/a12n37.pdf. Acesso em: 18 mar. 2014.

FURTADO, Celso. Formação econômica do Brasil. Rio de Janeiro: Editora Fundo de Cultura, 1959.

HOLANDA, Sérgio Buarque de. Raízes do Brasil. 11.ed. Rio de Janeiro: José Olympio Editora, 1977.

LAZZARINI, Sérgio G. Capitalismo de laços: os donos do Brasil e suas conexões. Rio de Janeiro: Elsevier, 2011.

LEFORT, Claude. Pensando o político: ensaios sobre a democracia, revolução e liberdade. Tradução de Eliane Souza. Rio de Janeiro: Paz e Terra, 1991.

LYNCH, Christian Edward Cyril; MENDONÇA, José Vicente Santos de. Por uma história constitucional brasileira: uma crítica pontual à doutrina da efetividade. Revista Direito e Práxis, v. 8, n. 2, p. 942-973, 2017. Disponível em:

http://www.e-publicacoes.uerj.br/index.php/revistaceaju/article/view/25654. Acesso em: 04 jan. 2018.

MARTINS, Clélia Aparecida. Sobre jogo de linguagem: Habermas e Wittgenstein. Revista de Filosofía (Madrid), v. 35, n. 2, p. 91-104, 2011. Disponível em:

http://revistas.ucm.es/index.php/RESF/article/view/9686. Acesso em: 05 dez. 2016. 
MUSACCHIO, Aldo; LAZZARINI, Sergio. Reinventando o capitalismo de Estado. O Leviatã nos negócios: Brasil e outros países. Tradução de Afonso Celso da Cunha Serra. 1.ed. São Paulo: Portfolio-Penguin, 2015.

NOBRE, Marcos. Imobilismo em movimento: Da abertura democrática ao governo Dilma. 1 ed. São Paulo: Companhia das Letras, 2013.

OLIVEIRA, Francisco de. Diálogo na grande tradição. In: NOVAES, Adauto (Org.) A crise do Estado-nação. Rio de Janeiro: Civilização Brasileira, 2003.

ORTEGA Y GASSET, José. Meditaciones del Quijote: con un apéndice inédito. Revista de Occidente en Alianza Editorial, 1981.

PRADO JÚNIOR, Caio. Formação do Brasil Contemporâneo. São Paulo: Editora Brasiliense, 1963.

PRADO JÚNIOR, Caio. História econômica do Brasil. 22 ed. São Paulo: Editora Brasiliense, 1979.

RIBEIRO, Darci. O povo brasileiro: a formação e o sentido do Brasil. São Paulo: Companhia das Letras, 2006.

SCHWARCZ, Lilia Moritz e STARLING, Heloisa Murgel. Brasil: uma biografia. 1.ed. São Paulo: Companhia das Letras, 2015.

SOUZA, Jessé. A ralé brasileira: quem é e como vive. Belo Horizonte: Editora UFMG, 2009.

STRECK, Lenio Luiz. Hermenêutica Jurídica e $(m)$ crise. Uma exploração hermenêutica da construção do Direito. 11.ed., atual. e ampliada. Porto Alegre: Livraria do Advogado Editora, 2014.

STRECK, Lenio Luiz. O Rubicão e os quatro ovos do condor: de novo, o que é ativismo? In: STRECK, Lenio Luiz; ROCHA, Leonel Severo; HENGELMANN, Wilson (Orgs.). Constituição, sistemas sociais e hermenêutica: anuário do Programa de Pós-graduação em Direito da Universidade do Vale do Rio dos Sinos - UNISINOS - Mestrado e Doutorado. Porto Alegre: Livraria do Advogado, 2016.

WITTGENSTEIN, Ludwig. Investigações Filosóficas. Tradução de José Carlos Bruni. São Paulo: Editora Nova Cultural, 1999. 


\section{DADOS DA PUBLICAÇÃO}

Categoria: artigo submetido ao double-blind review.

Recebido em: 02/08/2019.

Aceito em: 10/07/2020. 


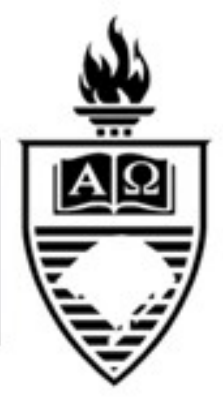

